\title{
DOUBLE-BALLOON ENTEROSCOPY IN THE DIAGNOSIS OF AN ADENOCARCINOMA OF THE FOURTH PORTION OF THE DUODENUM: REPORT OF A CASE
}

Adriana Vaz Safatle-Ribeiro, Tomazo Antonio Prince Franzini, Rogerio Kuga, Robson Kioshi Ishida, Elisa Ryoka Baba, Daniel Chaves Mendes, Shinichi Ishioka, Paulo Sakai.

\section{INTRODUCTION}

Primary adenocarcinoma of the duodenum is a rare condition representing around $0.5 \%$ of all gastrointestinal tract cancers. ${ }^{1-5}$ Adenocarcinomas are the most common histological type of malignant neoplasms of the duodenum accounting for $50 \%$ of the cases, followed by carcinoid, leiomyosarcomas and lymphomas. 4,6-8

Adenocarcinoma of the duodenum usually occurs between the sixth and seventh decades, ${ }^{4-6}$ and equal sex distribution is reported in the majority of the studied series. ${ }^{3,4}$ The second duodenal portion has the highest incidence of adenocarcinoma representing $74 \%$ of the cases, followed by third (13\%), fourth $(9 \%)$ and first $(4 \%)$ portions. ${ }^{4}$

The diagnosis of this disease is often delayed because symptoms and signs are nonspecific and vague, similar to those found in many benign conditions. ${ }^{3,5,7,9}$ In cases comprehending the third and fourth portions of the duodenum, the diagnosis may be even more delayed because endoscopic examination of the distal duodenum is poorly accomplished. ${ }^{9,10}$

We report a case of a 41-year-old man with primary adenocarcinoma of the fourth portion of the duodenum who presented with anemia and abdominal pain. His final diagnosis was confirmed with histological examination of biopsies performed through double-balloon enteroscopy (DBE).

\section{CASE REPORT}

A 41-year-old man was admitted to our hospital with a 3 -month history of anemia. At entry, full blood count results showed hemoglobin of $6.8 \mathrm{~g} / \mathrm{dl}$ and hematocrit of $22 \%$. This patient reported a weight loss of $40 \mathrm{~kg}$ over the previous four years, but no further investigation, such as

Endoscopy Unit - Department of Gastroenterology - University of São Paulo, São Paulo, SP, Brazil

E-mail: tomazof@uol.com.br abdominal CT or Barium meal radiography, was done before, due to a coincident bariatric jejunum-ileal bypass surgery at that time.

Upper gastrointestinal endoscopy showed antral erythematous gastritis, and no alteration was noted in the first or second portions of the duodenum. Fecal stool occult blood testing was positive (3+), but colonoscopy showed no alterations. Scintigraphy with $99 \mathrm{Tc}$ and marked erythrocytes was performed and revealed positivity for intestinal bleeding, probably at the proximal small bowel.

DBE demonstrated first, second and third portions of the duodenum with no abnormalities. In the fourth portion of the duodenum a vegetative, infiltrative and friable lesion was noted, extending about $10 \mathrm{~cm}$, involving almost all the circumference and the lumen of the organ, allowing however the transposition of the double-balloon enteroscope. Multiple biopsies were performed. Histological examination demonstrated moderately differentiated adenocarcinoma of the duodenum. The immunohistochemical evaluation was consistent with adenocarcinoma. After the diagnosis, the patient and his family elected treatment at a private hospital and we lost the follow-up.

\section{DISCUSSION}

Primary adenocarcinoma of the duodenum, excluding that of the ampulla of Vater is a rare condition that was first described in 1746 by Hamburgur. ${ }^{7}$ Duodenal adenocarcinoma arises in most of cases from the Lieberkühn epithelium of the duodenal mucosa. ${ }^{9}$ Various etiological and risk factors, such as familial adenomatous polyposis, Gardner's and Turcot's syndrome, Crohn's disease, celiac disease, polypoid lesions, Lynch's syndrome are related to duodenal adenocarcinoma. ${ }^{7,8,10}$ However, in this case the patient did not have any of the associated conditions.

The extreme rarity and the vagueness of presenting symptoms makes it hard to diagnose this tumor. The most fre- 
quent signs and symptoms found in patients with adenocarcinoma of the duodenum are abdominal pain, weight loss, nausea, anemia, and vomiting. ${ }^{3,4,7}$ In this patient, anemia and weight loss were present. This case raises an issue about the follow-up after bariatric surgery, since not all the symptoms might be correlated to the surgical procedure. Intensive care and meticulous diagnostic procedures after application of this technique should be the first priority.

Diagnostic methods may include x-ray films, abdominal CT, and more recently capsule endoscopy and DBE. Barium meal radiography may also be extremely valuable in identifying large endoluminal lesions. ${ }^{8-10} \mathrm{CT}$ is valuable for visualizing and staging the tumor. ${ }^{8}$ Conventional endoscopy may diagnose proximal tumors but is inadequate for distal duodenal tumors. ${ }^{9}$

DBE was described by Yamamoto et al., in 2001, and the system consists of an enteroscope, an overtube and a balloon pump controller. ${ }^{11}$ The double-balloon enteroscope has two balloons, one attached to the tip of the endoscope and another at the distal end of an overtube that facilitates the progression of the endoscope through the small bowel. Loops can be easily reduced by gentle withdrawal of the endoscope while the balloons are inflated. With this technique, the endoscope can be advanced by pushing it through the overtube allowing endoscopic visualization of the entire small bowel, biopsies and therapeutic intervention. ${ }^{12}$

The affected site of the duodenal portion is relevant (D1, D2, D3 and D4) for treatment and prognosis. D1 and D2 tumors should be treated with pancreatic-duodenal resection (PDR) and D3 and D4 tumors should be treated with local resections. A palliative bypass can be performed in non-resectable tumors with obstructive symptoms. ${ }^{1,2,4,7}$ Chemotherapy in the treatment of duodenal adenocarcinoma is not associated with good results and more studies are required on this subject. ${ }^{4}$ Some authors have reported a different prognosis based on the site of the tumor, which showed a better survival rate in the D3 and D4 forms. ${ }^{9}$ In fact, while the 5-year survival for all duodenal carcinomas ranges from $17 \%$ to $25 \%$, a review of the series confined to D3 and D4 reveals a 5-year survival of approximately $75 \% .{ }^{10}$ The different prognosis of proximal and distal tumors should be attributed to embryological factors. Although different embryological origins for the duodenal sections are not universally accepted, some authors describe D1 and D2 as arising from anterior intestine and D3, D4 from the middle intestine. ${ }^{7}$ Carcinomas arising in the anterior intestine have a more aggressive behavior. Moreover PDR usually performed in D1 and D2 resectable tumors also contributes to the lower survival rate, since it has higher morbidity and mortality. ${ }^{10}$

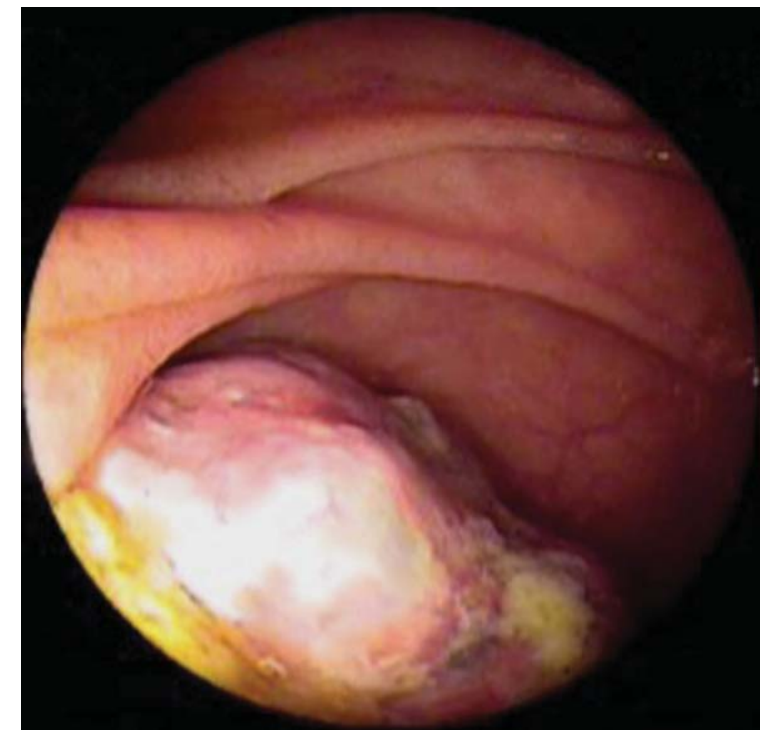

Figure 1. Vegetative lesion on the fourth portion of the duodenum

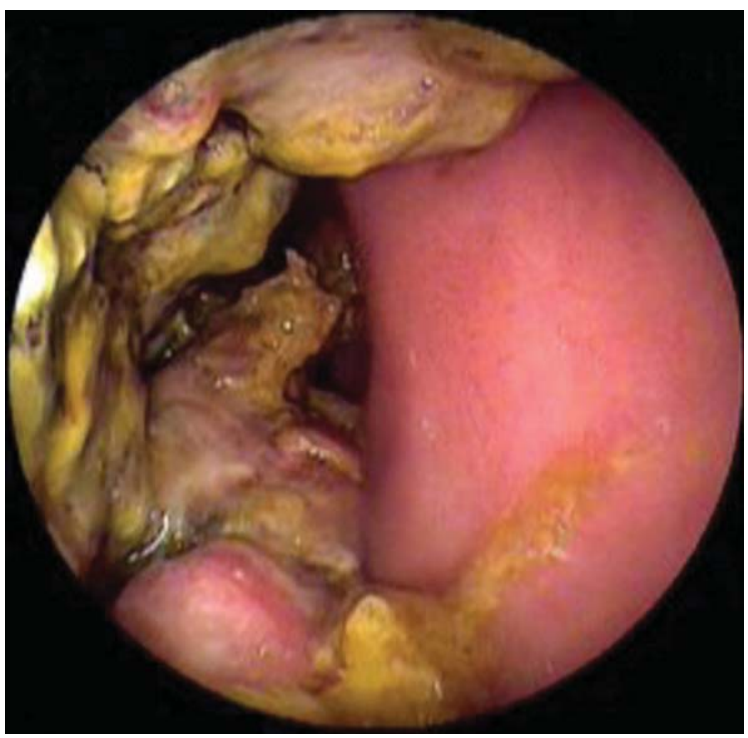

Figure 2. Primary adenocarcinoma of the duodenum

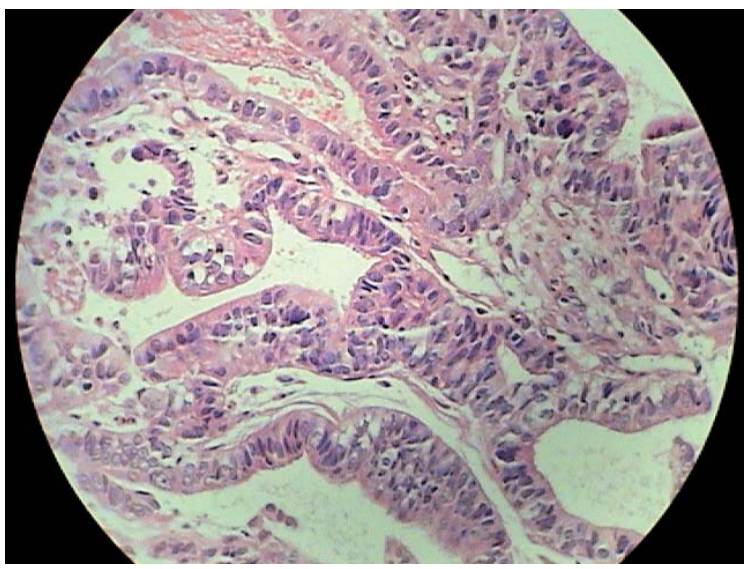

Figure 3. He (400 x) atipic glandular cells 
DBE is a safe and easily conducted method which permits full visualization of small bowel by using the oral or the anal route. ${ }^{13}$ For sedation, a combination of fentanyl, midazolam and propofol seems to be the best option. However, it is a time consuming procedure that has to be performed by two physicians; one controlling the overtube and the other managing the endoscope.

Prospective trials should be done in the near future to compare the efficacy of DBE versus capsule endoscopy regarding the diagnosis of small bowel disorders, in spite of the fact that endoscopic therapy is only achieved with DBE.

Therefore, in this case report, the usefulness of DBE was demonstrated. Through this technique, biopsies could be done to allow the histological examination of the lesion. Additionally, this case illustrates the need of close followup in bariatric surgery, as these patients may present with other diseases, such as neoplasias of the gastrointestinal tract, and hence the diagnosis may be delayed. It is noteworthy that these patients should be followed very closely, specially if they develop new symptoms.

\section{REFERENCES}

1. Ryder NM, Ko CY, Hines OJ, Gloor B, Reber HA. Primary duodenal adenocarcinoma: a 40-year experience. Arch Surg 2000; 135:10701075 .

2. Bakaeen FG, Murr MM, Sarr MG, Thompson GB, Farnell MB, Nagorney $\mathrm{DM}$, et al. What prognostic factors are important in duodenal adenocarcinoma? Arch Surg 2000; 135: 635-641.

3. Abrahams NA, Halverson A, Fazio VW, Rybicki LA, Goldblum JR. Adenocarcinoma of the small bowel. Dis Colon Rectum 2002; 45:14961502 .
4. Sadik Y, Culhaoglu AB, Ozdemir N. Carcinoma of the Fourth part of the duodenum: Report of a case. Jpn J Surg 1995; 25:1034-1037.

5. Tocchi A, Mazzoni G, Puma F, Miccini M, Cassini D, Bettelli E, et al. Adenocarcinoma of the third and fourth portions of the duodenum. Arch Surch 2003; 138:80-85.

6. Di Sario JA, Burt RW, Vargas H, Mcworter WP. Small Bowel Cancer: Epidemiological and clinical characteristics from a population-based registry. Am J Gastroenterol 1994; 89:699-701. 
7. Heniford BT, Iannitti DA, Evans P, Gagner M, Henderson JM. Primary Nonampulary/Periampulary adenocarcinoma of the duodenum. Am Surg 1998; 64:1165-1169.

8. Gill Satinder, Heuman Douglas, Mihas Anastasios A. Small Intestinal Neoplasms. J Clin Gastroenterol 2001; 33(4):267-282.

9. Santoro E, Sacchi M, Scutari F, Carboni F, Graziano F. Primary adenocarcinoma of the duodenum: treatment and survival in 89 patients. Hepatogastroenterology. 1997; 44:1157-1163.

10. Fronticelli CM, Bonghi F, Gattolin A, Ferrero A, Delsedime L. Primary adenocarcinoma of the Angle of Treitz: Case Report and Review of the Literature. Arch Surch 1996; 131:1109-1111.
11. Yamamoto H, Sekine Y, Sato Y, Higashizawa T, Miyata T, Iino S, et al. Total enteroscopy with a nonsurgical steerable double-balloon method. Gastrointest Endosc 2001; 53:216-220.

12. Yamamoto H, Kita H, Sunada K, Hayashi Y, Sato H, Yano T, et al Clinical Outcomes of double-balloon endoscopy for the diagnosis and treatment of small-intestinal diseases. Clin Gastroenterol Hepatol 2004; 2:1010-1016.

13. May A, Nachbar L, Ell C. Double-balloon enteroscopy (push-and-pull enteroscopy) of the small bowel: feasibility and diagnostic and therapeutic yield in patients with suspected small bowel diseases. Gastrointest Endosc 2005; 62:62-70. 